Document downloaded from:

http://hdl.handle.net/10251/150367

This paper must be cited as:

Riedemann, J.; Clare, J.; Wheeler, P.; Blasco-Gimenez, R.; Cardenas, R.; Peña, R. (2016). Vector control of an open-ended winding induction machine based on a two-output indirect matrix converter. EPE Journal. 26(3):104-112. https://doi.org/10.1080/09398368.2016.1261457

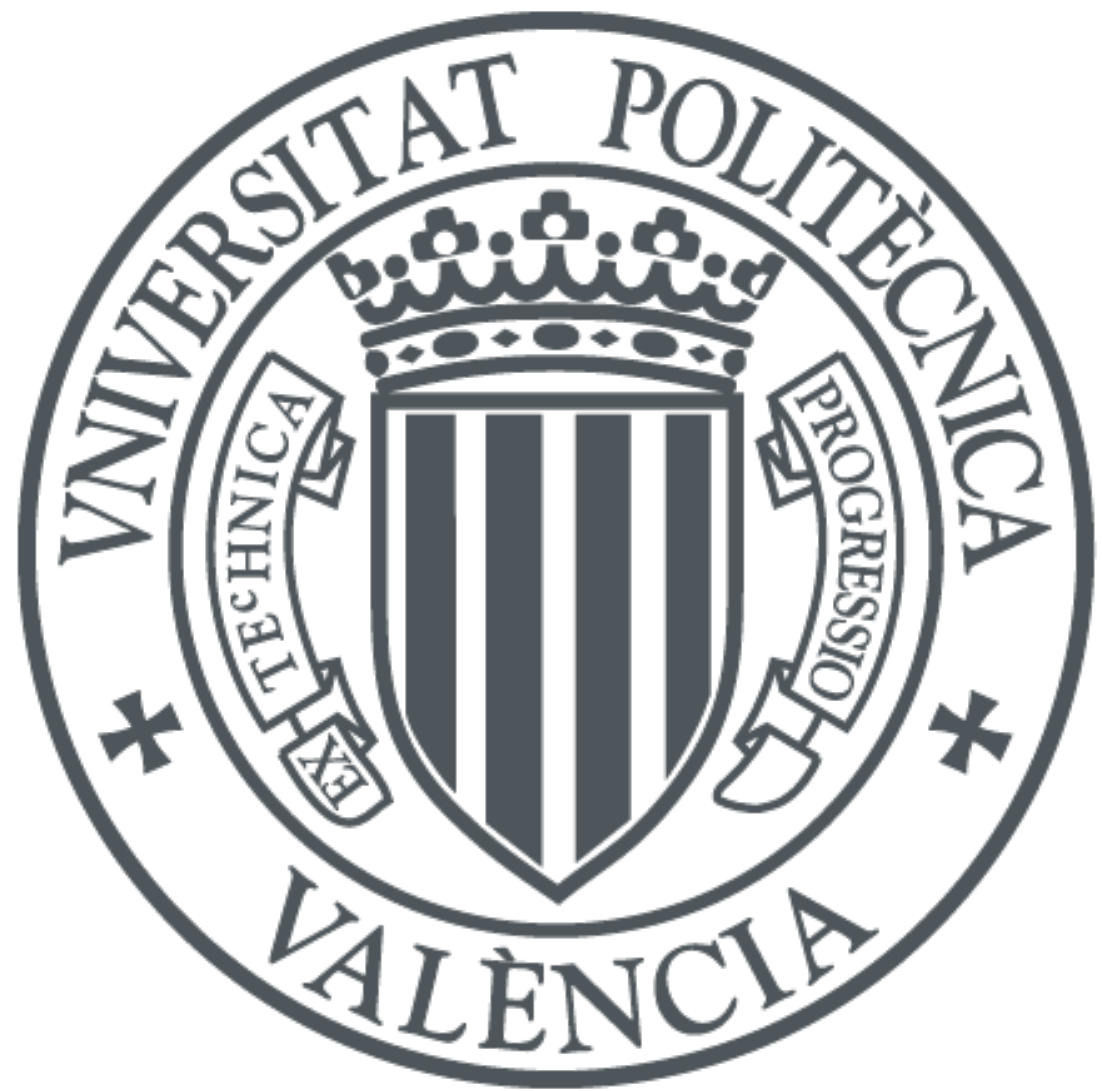

The final publication is available at

https://doi.org/10.1080/09398368.2016.1261457

Copyright Taylor \& Francis

Additional Information 


\title{
Vector control of an open-ended winding induction machine based on a two-output indirect matrix converter
}

\author{
Javier Riedemann \\ UNIVERSITY OF BÍO-BÍO \\ Concepción, Chile \\ jriedema@ubiobio.cl
Ramón Blasco-Gimenez
UNIVERSITAT POLITECNICA
DE VALENCIA
Valencia, Spain
rblasco@upv.es

\author{
Jon Clare, Pat Wheeler \\ UNIVERSITY OF NOTTINGHAM \\ Nottingham, U.K. \\ \{jon.clare,pat.wheeler\}@ nottingham.ac.uk
Roberto Cárdenas
UNIVERSITY OF
CHILE \\ Santiago, Chile \\ rcd@ieee.org
}

\section{Acknowledgements}

This work was funded by The Chilean Research Fondecyt Grant 1151325. The financial support given by CONICYT/FONDAP/15110019 is also acknowledged.

\section{Keywords}

«Matrix converter», «Electrical drive», «Pulse Width Modulation (PWM)»

\begin{abstract}
The open-ended winding induction machine fed from a standard two-level Voltage Source Inverter (VSI) arrangement is an attractive solution for AC drives. An alternative power converter approach is to use an Indirect Matrix Converter (IMC) consisting of a matrix converter AC-DC input stage and two VSI output stages. This latter topology provides fully bidirectional power flow operation and requires only a small input filter. In this paper, a vector control strategy for an open-ended winding cage induction machine fed by a two-output IMC is presented. The modulation scheme for the input power converter stage aims to modify the virtual DC link voltage depending on the load voltage requirement. Additionally, the modulation strategy for the dual-inverter output aims to eliminate the zero sequence voltage applied to the load. A vector control scheme is used and the full system is modelled using a PSIM and MATLAB/Simulink platform. Experimental results from a $7.5 \mathrm{~kW}$ prototype are presented, demonstrating the feasibility of the topology and control strategy.
\end{abstract}

\section{Introduction}

An open-ended winding induction machine fed by a dual-inverter topology [1], offers several advantages when compared to a standard star or delta connected AC machine. The main features can be summarized as [1]-[2]: equal power input from both sides of each winding, thus each VSI is rated at half the machine power rating; each phase stator current can be controlled independently; possibility to have twice the effective switching frequency (depending on the modulation strategy); extensibility to more phases, therefore multiphase induction machines can be considered if current reduction is required; possibility of reducing common-mode voltage; and a certain degree of fault tolerance, as there is voltage space vector redundancy.

However, an open-ended winding induction machine drive can have some drawbacks, such as [1]: possibility of zero sequence current flowing in the machine because of the occurrence of zero sequence voltage; increased conduction losses; more complex power converter requirements, i.e. more power devices, gate drive circuits, etc. Recently, significant research effort has been focused on direct frequency changing power converters, such as the Matrix Converter (MC) [3] or the Indirect Matrix Converter [4]. It is known that these power converter topologies offer a suitable solution for direct 
AC-AC conversion, achieving sinusoidal input and output currents, bidirectional power flow capability and controllable input power factor, without using bulky energy storage elements [4]. Matrix converters have also been utilized to supply open-ended winding AC machines such as reported in [5].

Several works have been focused on investigating the control of open-end winding machines based on two standard VSIs supplied by a single DC source. For instance, in [7] a deadbeat current controller is proposed aiming for a high bandwidth control loop and in [8] a predictive torque control scheme with zero-sequence current suppression is presented.

In this paper, a vector control scheme is presented for an open-ended winding induction machine using a topology consisting in a two-output IMC. A schematic of the proposed topology is shown in Fig. 1. The modulation strategy for the output stages is based on voltage space vectors and suppresses the zero sequence voltage applied to the load [9], thus avoiding the circulation of zero sequence current in the machine windings. The capability of the input rectifier to produce different virtual DC voltages is exploited [10]. If the virtual DC voltage is reduced, then commutations of the output VSIs can take place at lower voltages. Therefore, depending on the machine operating conditions, the modulation of the input stage is changed in order to obtain a lower/higher DC voltage without causing over modulation. Preliminary work discussing the application of this topology to an open-ended winding cage induction machine was presented in [11] and the concept is further developed and verified in this paper. The proposed control system is modelled using a PSIM/MATLAB platform and experimentally verified in a $7.5 \mathrm{~kW}$ experimental rig. Simulation and experimental results are presented and discussed.

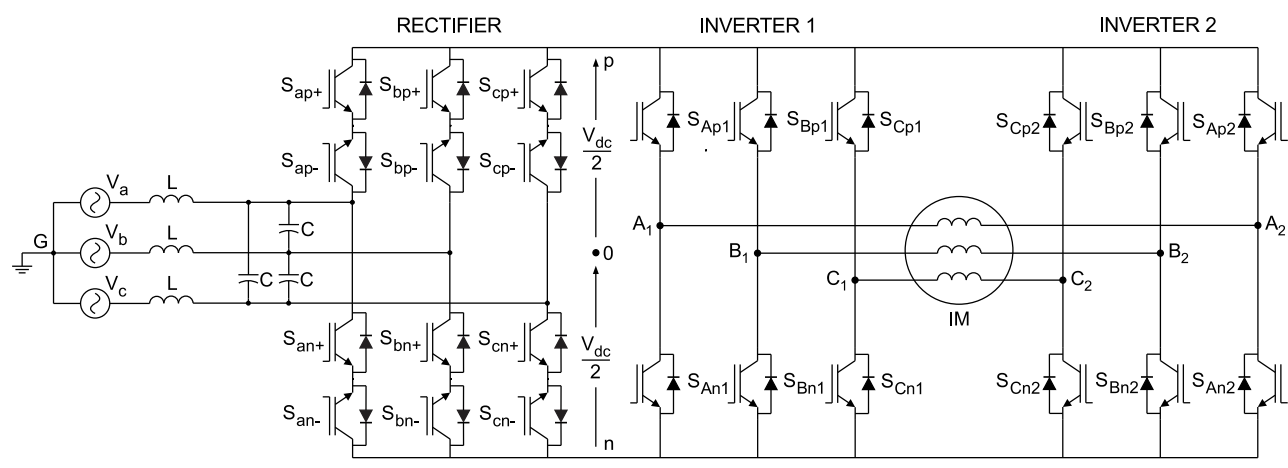

Fig. 1: Two-output IMC feeding an open-ended winding induction machine

\section{Modulation for the input stage of the IMC}

The modulation strategy for the rectifier input stage aims to produce a positive DC link voltage in each sampling period and unity displacement factor at the input [12]. Additionally, the duty cycles calculated in the switching pattern should produce sinusoidal currents at the converter input.

Two different SVM strategies can be used for the rectifier [12] giving the DC link voltage waveforms shown in Fig. 2. Usually, the input stage of an IMC is modulated to maximize the DC voltage by commutating between the largest and second largest positive input line voltages [13] (Fig. 2a). However, if the overall converter output voltage requirement is low, the rectifier can be modulated to produce a reduced DC voltage by commutating between the lowest and second lowest input line voltages [13] (Fig. 2b); this strategy allows the input and output stages of the power converter to commutate with lower voltage and reduces the switching losses.

To maximize the DC link voltage, the sector assignment defined in Fig. 3a should be considered [10]. Alternatively, if a reduced DC link voltage is required, the sector assignment defined in Fig. 3b should be used [10]. In both cases, $\underline{i}_{r e f}$ is a current reference vector for the rectifier SVM that is usually aligned with the input voltage vector to obtain unity input displacement factor. 


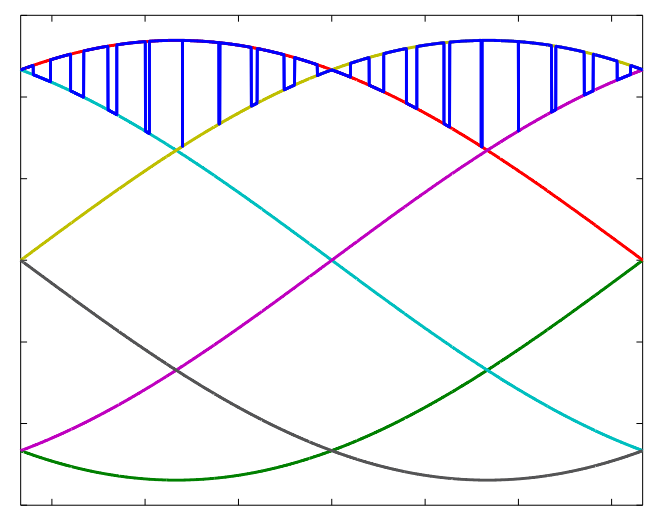

a)

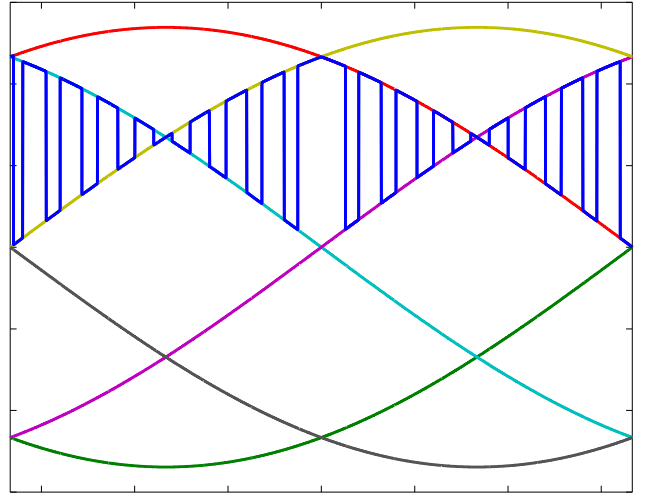

b)

Fig. 2: Modulation strategy to achieve (a) maximum DC voltage and (b) reduced DC voltage

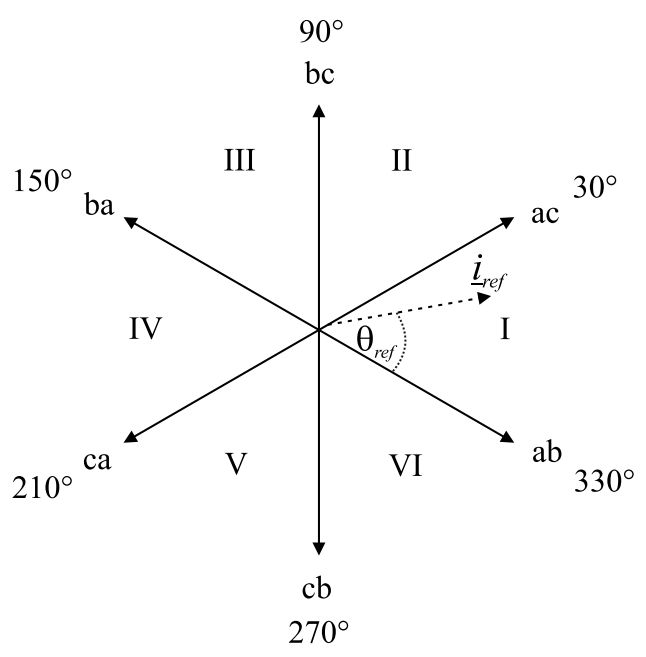

a)

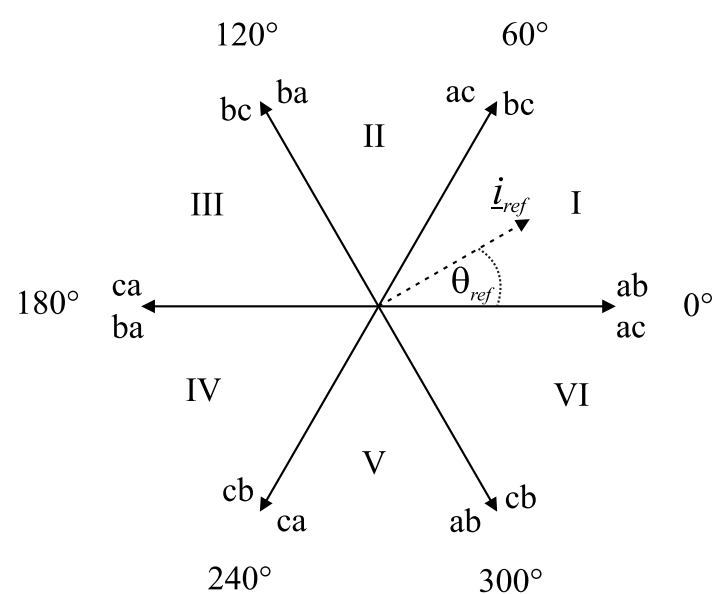

b)

Fig. 3: Space vector locations for (a) maximum DC voltage and (b) reduced DC voltage

Defining $\theta_{r e f, i}$ as the angle of the voltage reference vector, the $\gamma-\delta$ duty cycles for both modulation strategies are given in (1) - (3). Further details about modulation strategies for the input stage can be found in [10], [12].

$$
d_{\gamma}^{R}=\frac{d_{\gamma}}{d_{\gamma}+d_{\delta}}, \quad d_{\delta}^{R}=\frac{d_{\delta}}{d_{\gamma}+d_{\delta}}
$$

where

$$
d_{\gamma}=\sin \left(\pi / 3-\theta_{\text {ref }, i}\right), d_{\delta}=\sin \left(\theta_{\text {ref }, i}\right)
$$

are the duty cycles for maximum DC voltage and

$$
d_{\gamma}=\cos \left(\theta_{\text {ref }, i}\right), \quad d_{\delta}=\cos \left(\pi / 3-\theta_{\text {ref }, i}\right)
$$

are the duty cycles for reduced DC voltage. Fig. 4a illustrates a transition from reduced DC voltage to maximum DC voltage while Fig. 4b shows the opposite situation. 


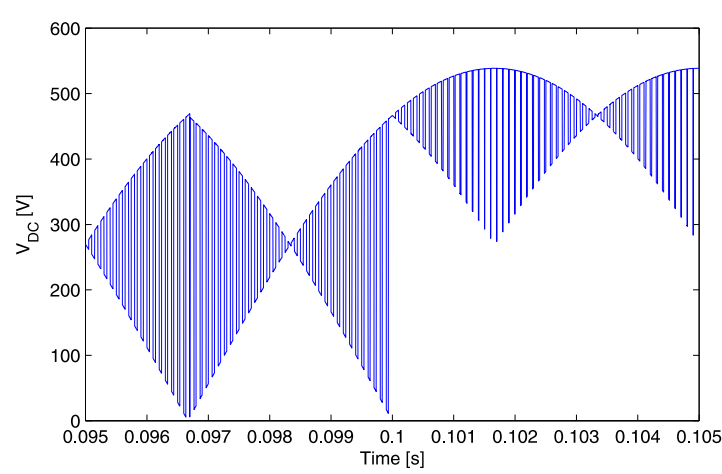

a)

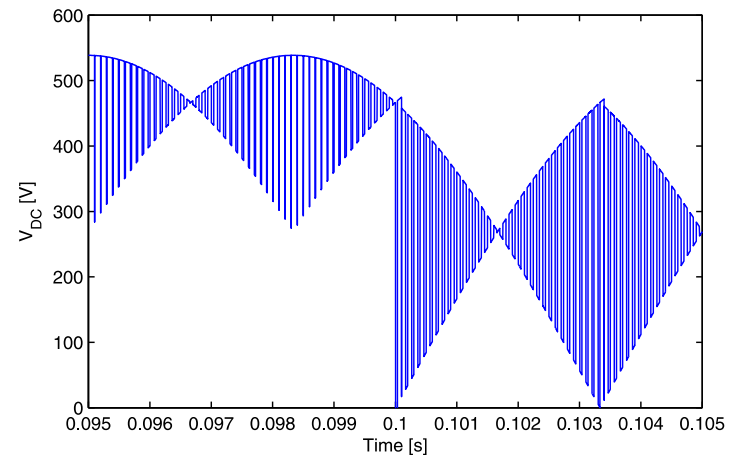

b)

Fig. 4: Transitions between low and high voltage rectifier modulation strategies.

The rectifier SVM for reduced DC link voltage decreases the voltage gain by a factor of $\sqrt{3}$. Thus, the transition between reduced and maximum DC link voltage should take place when the output voltage reference is higher than $\frac{1.5}{\sqrt{3}} \cdot V_{p h, \text { input }}=0.866 \cdot V_{\text {ph, input }}$.

\section{Modulation for the output stage of the IMC}

As mentioned before, the dual-inverter fed open-ended winding induction motor drive may suffer from zero sequence current flow caused by application of zero sequence voltage. This zero sequence voltage is produced because of the asymmetry of the instantaneous phase voltages applied to the machine windings (due to the voltage space vectors used). In general, zero sequence currents may give rise to increased RMS phase current, thus increasing the system losses; increased current/voltage THD and machine overheating and vibration. The zero sequence voltage is given by [14]:

$$
v_{z S}=\frac{v_{A 1 A 2}+v_{B 1 B 2}+v_{C 1 C 2}}{3}
$$

For the topology depicted in Fig, 1, the aim of the modulation strategy for the output stages is to eliminate the load zero sequence voltage [15], whilst providing the desired machine phase voltages. The voltage vectors for inverter 1 are shown in Table I; the same space vectors are valid for inverter 2 but with superscript 2 .

Table I: Switching states of the individual inverters

\begin{tabular}{|l|l|l|l|}
\hline \multicolumn{5}{|c|}{ States of inverter $\mathbf{1}\left[\begin{array}{l}\boldsymbol{S}_{\boldsymbol{A} \mathbf{}} \boldsymbol{S}_{\boldsymbol{B} 1} \boldsymbol{S}_{\boldsymbol{C} \mathbf{1}}\end{array}\right]$} \\
\hline$V_{1}^{1}=\left[\begin{array}{lll}1 & 0 & 0\end{array}\right]$ & $V_{2}^{1}=\left[\begin{array}{lll}1 & 1 & 0\end{array}\right]$ & $V_{3}^{1}=\left[\begin{array}{lll}0 & 1 & 0\end{array}\right]$ & $V_{4}^{1}=\left[\begin{array}{lll}0 & 1 & 1\end{array}\right]$ \\
\hline$V_{5}^{1}=\left[\begin{array}{lll}0 & 0 & 1\end{array}\right]$ & $V_{6}^{1}=\left[\begin{array}{lll}1 & 0 & 1\end{array}\right]$ & $V_{7}^{1}=\left[\begin{array}{lll}1 & 1 & 1\end{array}\right]$ & $V_{8}^{1}=\left[\begin{array}{lll}0 & 0 & 0\end{array}\right]$ \\
\hline
\end{tabular}

Let $V_{i j}=\left[V_{i}^{1} V_{j}^{2}\right]$ with $i, j=1 \ldots 8$, be the phase voltage vector combination of the dual-inverter output; the zero sequence voltage contributions from the 64 space vector combinations are shown in Table II.

As can be noted from Table II, there are twenty space vector combinations of the dual-inverter topology that do not produce any zero sequence voltage. Moreover, it can be found that there are two different but totally equivalent (same magnitude and direction) sets of active vectors producing null $v_{z s}$ [9]; these sets are given in Table III. 
Table II: Zero sequence voltage contributions from different space vector combinations

\begin{tabular}{|c|c|}
\hline $\boldsymbol{V}_{\boldsymbol{z s}}$ & Voltage vector combinations \\
\hline$-\boldsymbol{V}_{\boldsymbol{D C}} / \mathbf{2}$ & $V_{87}$ \\
\hline$-\boldsymbol{V}_{\boldsymbol{D C}} / \mathbf{3}$ & $V_{84}, V_{86}, V_{82}, V_{57}, V_{37}, V_{17}$ \\
\hline$-\boldsymbol{V}_{\boldsymbol{D C}} / \mathbf{6}$ & $V_{85}, V_{83}, V_{54}, V_{34}, V_{81}, V_{56}, V_{52}, V_{36}$ \\
& $V_{32}, V_{47}, V_{14}, V_{16}, V_{12}, V_{67}, V_{27}$ \\
\hline $\mathbf{0}$ & $\begin{array}{c}V_{88}, V_{55}, V_{53}, V_{35}, V_{33}, V_{44}, V_{51}, V_{31}, V_{46}, V_{42} \\
V_{15}, V_{13}, V_{64}, V_{24}, V_{11}, V_{66}, V_{62}, V_{26}, V_{22}, V_{77}\end{array}$ \\
\hline$+\boldsymbol{V}_{\boldsymbol{D C}} / \mathbf{6}$ & $\begin{array}{r}V_{58}, V_{38}, V_{45}, V_{43}, V_{18}, V_{65}, V_{25}, V_{63} \\
V_{23}, V_{74}, V_{41}, V_{61}, V_{21}, V_{76}, V_{72}\end{array}$ \\
\hline$+\boldsymbol{V}_{\boldsymbol{D C}} / \mathbf{3}$ & $V_{48}, V_{68}, V_{82}, V_{75}, V_{73}, V_{71}$ \\
\hline$+\boldsymbol{V}_{\boldsymbol{D C}} / \mathbf{2}$ & $V_{78}$ \\
\hline
\end{tabular}

Table III: Sets of active vectors which do not produce zero sequence voltage

\begin{tabular}{|c|c|c|c|}
\hline \multicolumn{2}{|c|}{ Set 1} & \multicolumn{2}{|c|}{ Set 2} \\
\hline$V_{15}=\left[\begin{array}{llllll}1 & 0 & 0 & 0 & 0 & 1\end{array}\right]$ & $V_{51}=\left[\begin{array}{llllll}0 & 0 & 1 & 1 & 0 & 0\end{array}\right]$ & $V_{24}=\left[\begin{array}{llllll}1 & 1 & 0 & 0 & 1 & 1\end{array}\right]$ & $V_{42}=\left[\begin{array}{lllllll}0 & 1 & 1 & 1 & 1 & 0\end{array}\right]$ \\
\hline$V_{35}=\left[\begin{array}{llllll}0 & 1 & 0 & 0 & 0 & 1\end{array}\right]$ & $V_{53}=\left[\begin{array}{llllll}0 & 0 & 1 & 0 & 1 & 0\end{array}\right]$ & $V_{26}=\left[\begin{array}{llllll}1 & 1 & 0 & 1 & 0 & 1\end{array}\right]$ & $V_{62}=\left[\begin{array}{llllll}1 & 0 & 1 & 1 & 1 & 0\end{array}\right]$ \\
\hline$V_{31}=\left[\begin{array}{llllll}0 & 1 & 0 & 1 & 0 & 0\end{array}\right]$ & $V_{13}=\left[\begin{array}{llllll}1 & 0 & 0 & 0 & 1 & 0\end{array}\right]$ & $V_{46}=\left[\begin{array}{llllll}0 & 1 & 1 & 1 & 0 & 1\end{array}\right]$ & $V_{64}=\left[\begin{array}{llllll}1 & 0 & 1 & 0 & 1 & 1\end{array}\right]$ \\
\hline
\end{tabular}

The zero vectors are mapped depending on the sector information [9] according to the mapping shown in Table IV.

Table IV: Mapping of zero vectors

\begin{tabular}{|l|c|c|c|c|c|c|}
\hline Sector & I & II & III & IV & V & VI \\
\hline Set 1 zero vectors & $V_{55}$ & $V_{33}$ & $V_{11}$ & $V_{55}$ & $V_{33}$ & $V_{11}$ \\
\hline Set 2 zero vectors & $V_{22}$ & $V_{66}$ & $V_{44}$ & $V_{22}$ & $V_{66}$ & $V_{44}$ \\
\hline
\end{tabular}

The duty cycles for the output stage are calculated from:

$$
d_{\alpha}=m(t) \sin \left(\pi / 3-\theta_{\text {ref,o }}\right) \quad, \quad d_{\beta}=m(t) \sin \left(\theta_{\text {ref,o }}\right) \quad \text { and } \quad d_{0}=1-d_{\alpha}-d_{\beta}
$$

where $m(t)=m_{o}\left(d_{\gamma}+d_{\delta}\right)$. The term $d_{\gamma}+d_{\delta}$ is included to compensate the fluctuations of the DC link voltage; $m_{o}$ is the modulation index $\left(0 \leq m_{o} \leq 1\right)$ and $\theta_{r e f, o}$ is the angle of the output reference voltage space vector. To obtain a correct balance of the input currents and the output voltages in each switching period, the modulation pattern should employ all combinations of the rectification and the inversion switching states [12], resulting in the following duty cycles for the active vectors:

$$
d_{\alpha \gamma}=d_{\alpha} d_{\gamma}^{R}, d_{\beta \gamma}=d_{\beta} d_{\gamma}^{R}, d_{\alpha \delta}=d_{\alpha} d_{\delta}^{R}, d_{\beta \delta}=d_{\beta} d_{\delta}^{R}
$$

The total zero vector duty cycle is:

$$
d_{0}=1-d_{\alpha}-d_{\beta}
$$

and the combined zero vectors duty cycles are:

$$
d_{0 \gamma}=d_{0} d_{\gamma}^{R}, d_{0 \delta}=d_{0} d_{\delta}^{R}
$$

Thus, the switching sequence, which is the same for both output stages, is shown in Fig. 5, commutating the input stage with zero DC current. 


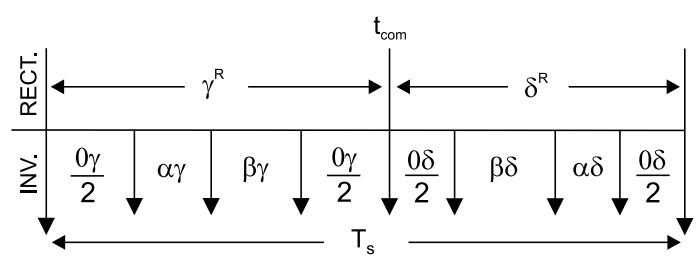

Fig. 5: Standard switching sequence for IMCs

\section{Vector control of the machine currents}

The machine currents are controlled using a standard indirect feedforward vector control [16]. Fig. 6 shows the control scheme.

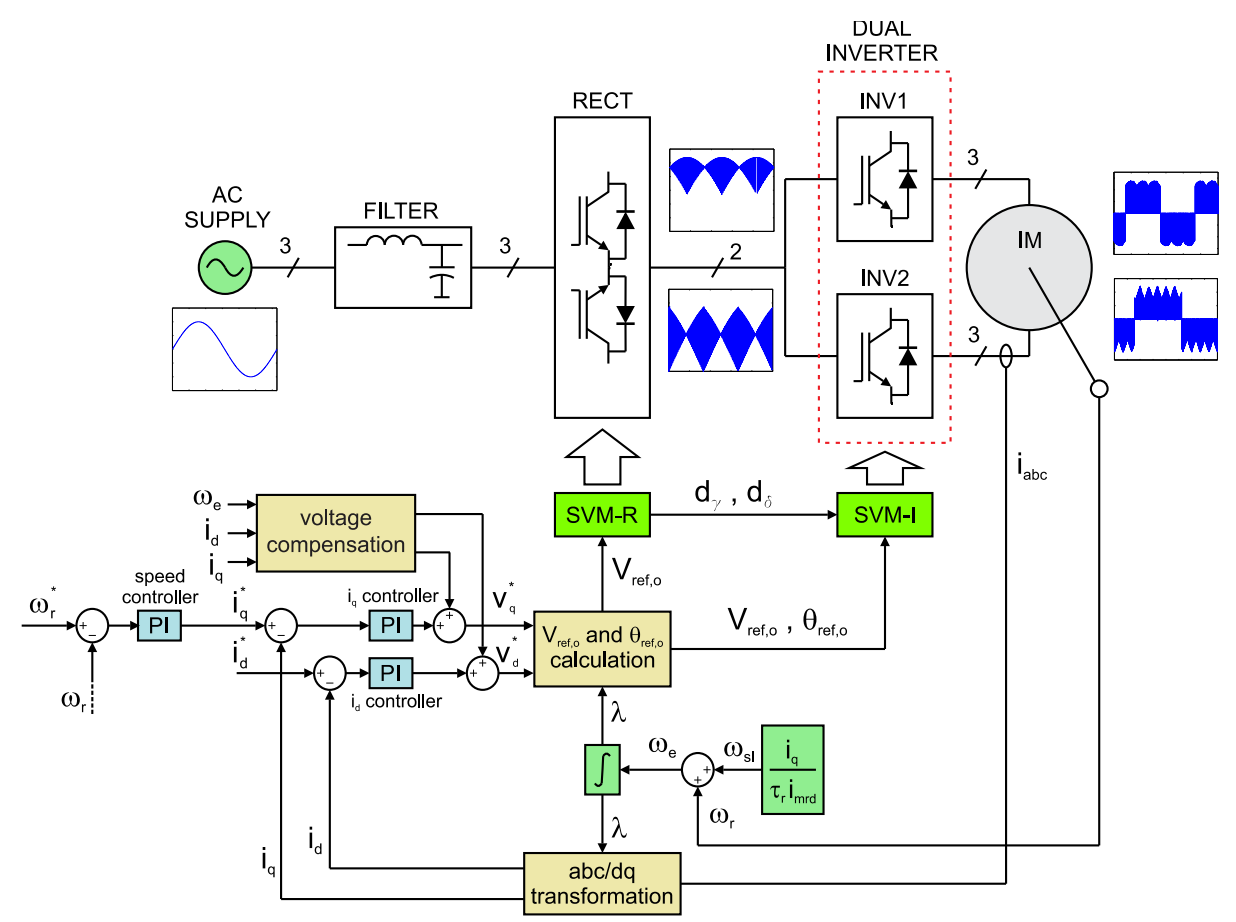

Fig. 6: Feedforward vector control scheme of induction machine

\section{Simulation results}

The system has been modelled and simulated using PSIM. The results obtained in PSIM are then plotted and analyzed in the MATLAB environment. The parameters used in the simulation work (which are equivalent to those used in the experimental rig), are depicted in Table V.

The PI current controllers are designed for a natural frequency $f_{o}=70 \mathrm{~Hz}$ and a damping coefficient of $\xi=0.8$.

Table V: System parameters

\begin{tabular}{|c|l|c|}
\hline Variable & \multicolumn{1}{|c|}{ Description } & Value \\
\hline$P_{m}$ & Machine power & $7.5 \mathrm{~kW}$ \\
\hline$V_{m, p h}$ & Machine phase voltage & $220 \mathrm{~V}$ \\
\hline$V_{s}$ & Input phase voltage & $100 \mathrm{~V}$ \\
\hline$f$ & Input voltage frequency & $50 \mathrm{~Hz}$ \\
\hline$f_{S}$ & Switching frequency & $10 \mathrm{kHz}$ \\
\hline$C_{f}$ & Input filter capacitance & $2 \mu \mathrm{F}$ \\
\hline$L_{f}$ & Input filter inductance & $0.5 \mathrm{mH}$ \\
\hline
\end{tabular}


The performance of the vector control scheme is verified by applying step changes in the $d q$-axis reference currents with a motor speed of $500 \mathrm{rpm}$. Moreover, the modulation of the converter input rectifier changes from reduced DC voltage to maximum DC voltage when a step change is applied in the $d q$ reference currents. Fig. $7-9$ show the waveforms obtained by applying a step change in the $q$ axis reference current from $7.7 \mathrm{~A}$ to $10 \mathrm{~A}$ at $t=0.16 \mathrm{~s}$, while the $d$-axis current is kept constant at 6 A. Fig. 7a shows $d q$ reference currents and their corresponding responses. Good tracking of the reference stator currents is obtained. The motor currents and phase- $a$ voltage are shown in Fig. 7b. The step change in $q$-axis current is followed with changes in the magnitude and phase of the instantaneous machine currents. Moreover, a transition between reduced virtual DC voltage to maximum virtual DC voltage can be noticed in the output phase voltage of Fig. $7 \mathrm{~b}$ (bottom).
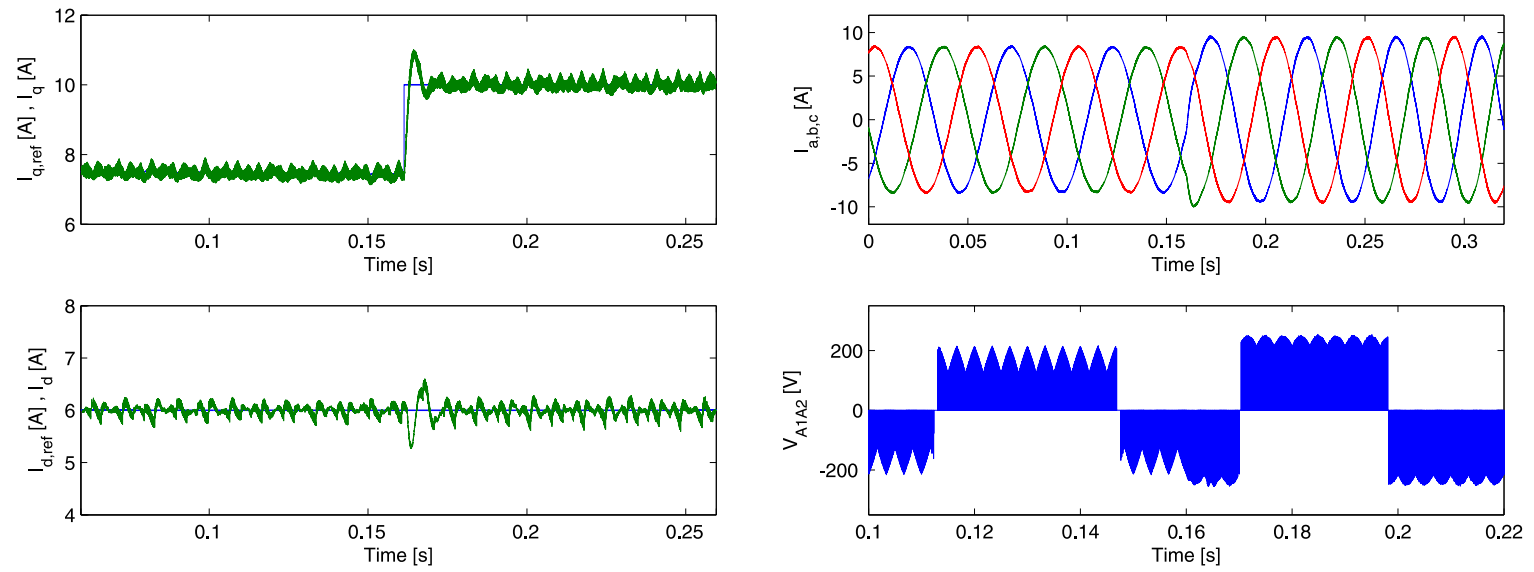

a)

b)

Fig. 7: $q$-axis current step change. a) Motor $q$ axis current (top) and $d$-axis current (bottom). b) Motor currents (top) and phase voltage (bottom)

Fig. 8a shows the performance of the control scheme when a step change from $6 \mathrm{~A}$ to $8 \mathrm{~A}$ is applied in the $d$-axis reference current while the $q$-axis current is kept constant at 7.7 A. The motor currents and phase- $a$ voltage are shown in Fig. 8b. Again the transition between both modulation strategies for the input rectifier can be noticed.
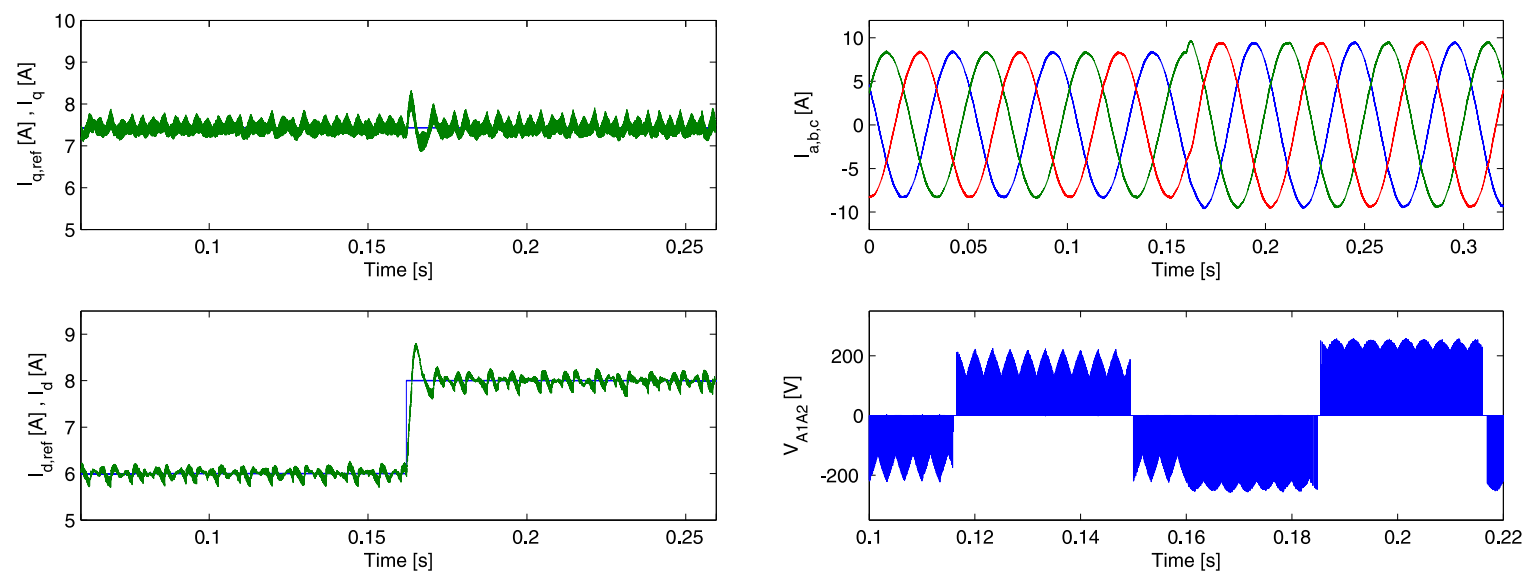

a)

b)

Fig. 8: $d$-axis current step change. a) Motor $q$ axis current (top) and $d$-axis current (bottom). b) Motor currents (top) and phase voltage (bottom)

Fig. 9 (top) shows the converter input phase voltage and current, illustrating that unity input displacement factor is achieved. Fig. 9 (bottom) shows the output zero sequence voltage that has been 
obtained by applying (4) to the measured voltage across the load in each phase. As can be seen, the zero sequence voltage has been eliminated due to the modulation strategy used for the output stages.
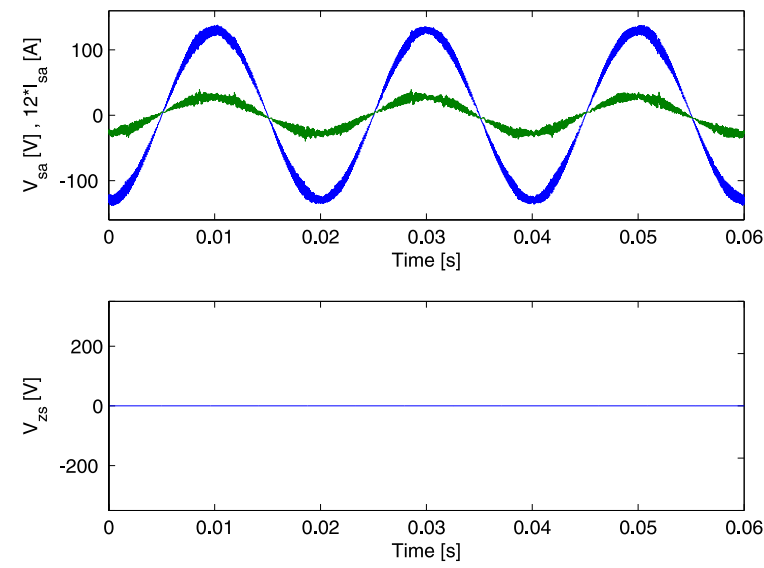

Fig. 9: Input phase voltage and current (top) and zero sequence voltage (bottom)

\section{Experimental Results}

The proposed strategy has been tested using the experimental system shown in Fig. 10. The IMC was designed and built at the University of Nottingham Power Electronics, Machines and Control Group lab facilities. A six-pole induction machine rated at $7.5 \mathrm{~kW}$ is used. A DSP board, based on the TMS320C6713 processor, is used as the control platform. The calculation of duty cycles is carried out on the DSP among several other tasks. An FPGA interface board, designed at Nottingham University, is used to implement the modulation strategies and data acquisition. Communication between the DSP and a PC is achieved using a DSK6713HPI (Host Port Interface) daughter card. The converter input stage uses SK60GM123 modules and the output stages use SK35GD126 modules. The switching frequency is $10 \mathrm{kHz}$ and voltages and currents are also sampled at $10 \mathrm{kHz}$.

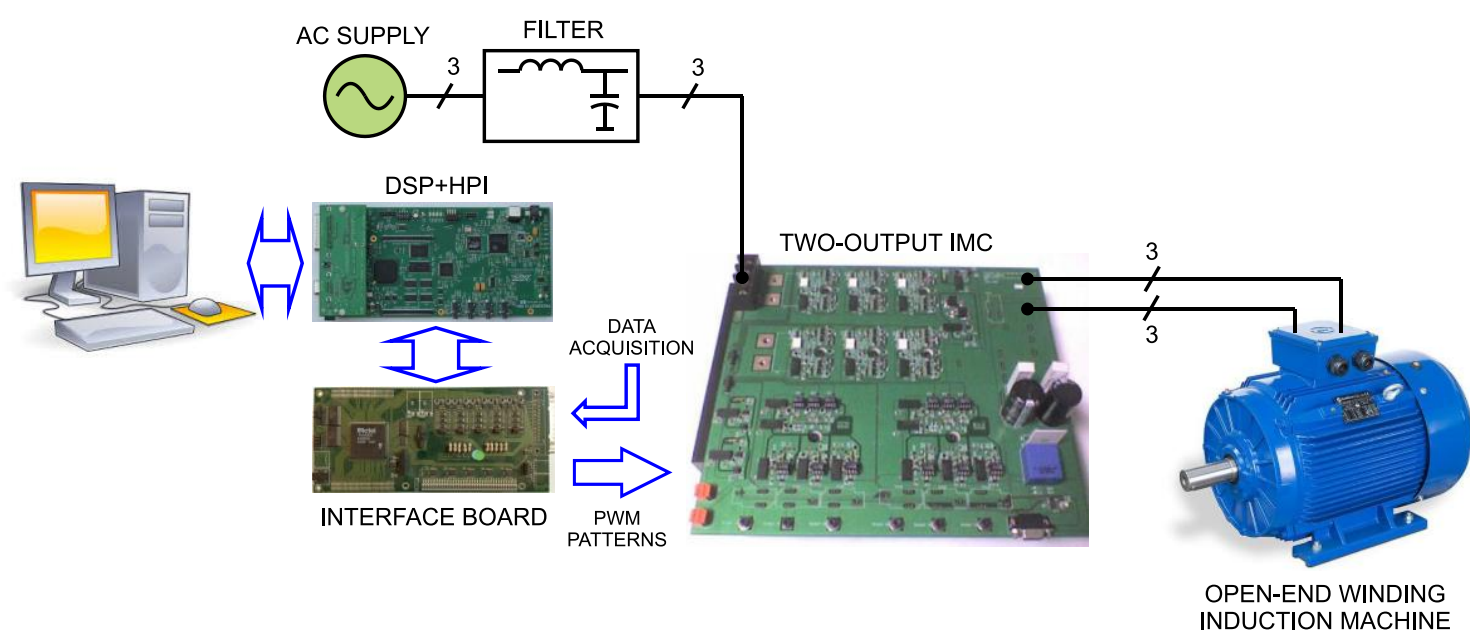

Fig. 10: Experimental system

The voltages and currents have been measured using a Yokowaga DL850 ScopeCorder, using three, two channel, 12 bit, high speed $100 \mathrm{Ms} / \mathrm{s}$ modules for voltage measurements and two $12 \mathrm{bit}$, two channel, $10 \mathrm{Ms} / \mathrm{s}$ modules for current measurements. The load used in the experimental system is a DC generator, coupled to the induction motor shaft, supplying a resistive load. The test conditions for the experimental results obtained are the same of the simulation system, i.e. the machine running at 500rpm and step changes in $d q$ axis reference currents. The modulation strategy of the input rectifier is changed when step reference currents occur, from reduced to maximum DC voltage. 
The performance of the $d q$-axis current controllers is shown in Fig. 11a. The $\mathrm{d}$ axis current is regulated at $6 \mathrm{~A}$ and initially the $q$-axis current is regulated at $7.7 \mathrm{~A}$. At $\mathrm{t}=0.16 \mathrm{~s}$ the reference $q$-axis current is increased to $10 \mathrm{~A}$. The instantaneous motor currents and phase- $a$ voltage are shown in Fig. 11b. Again the transition between both rectifier modulation strategies can be seen in the output phase voltage (Fig. 11b bottom) when the change in $q$-axis reference current is applied. Good performance of the current control scheme can be seen and good agreement is observed with the simulation results (compare with Fig. 7).
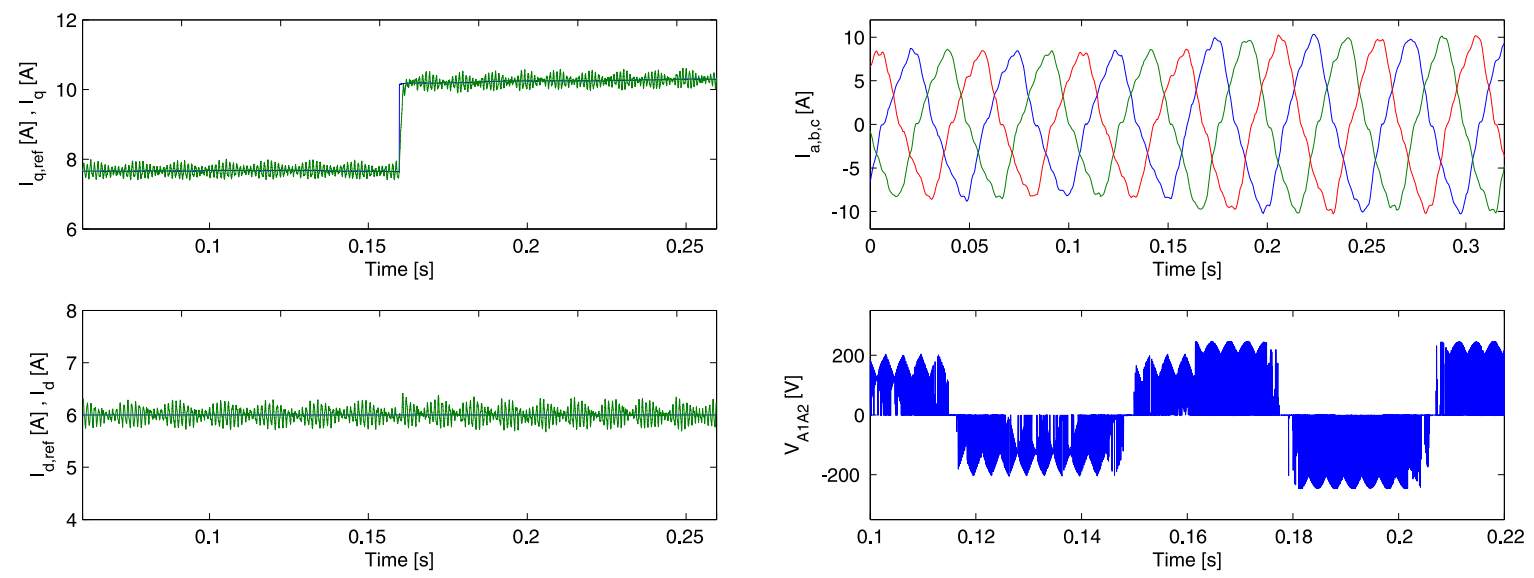

a)

b)

Fig. 11: $q$-axis current step change. a) Motor $q$-axis current (top) and $d$-axis current (bottom). b) Motor currents (top) and phase voltage (bottom)

Fig. 12a shows the $d q$ machine currents when a step change in $d$-axis reference current is applied while the $q$-axis reference current is kept constant at 7.7 A. The motor currents and phase- $a$ voltage are shown in Fig. 12b. Again, good performance of the current control strategy is observed and the results are in agreement with the ones obtained through simulation (compare with Fig. 8).
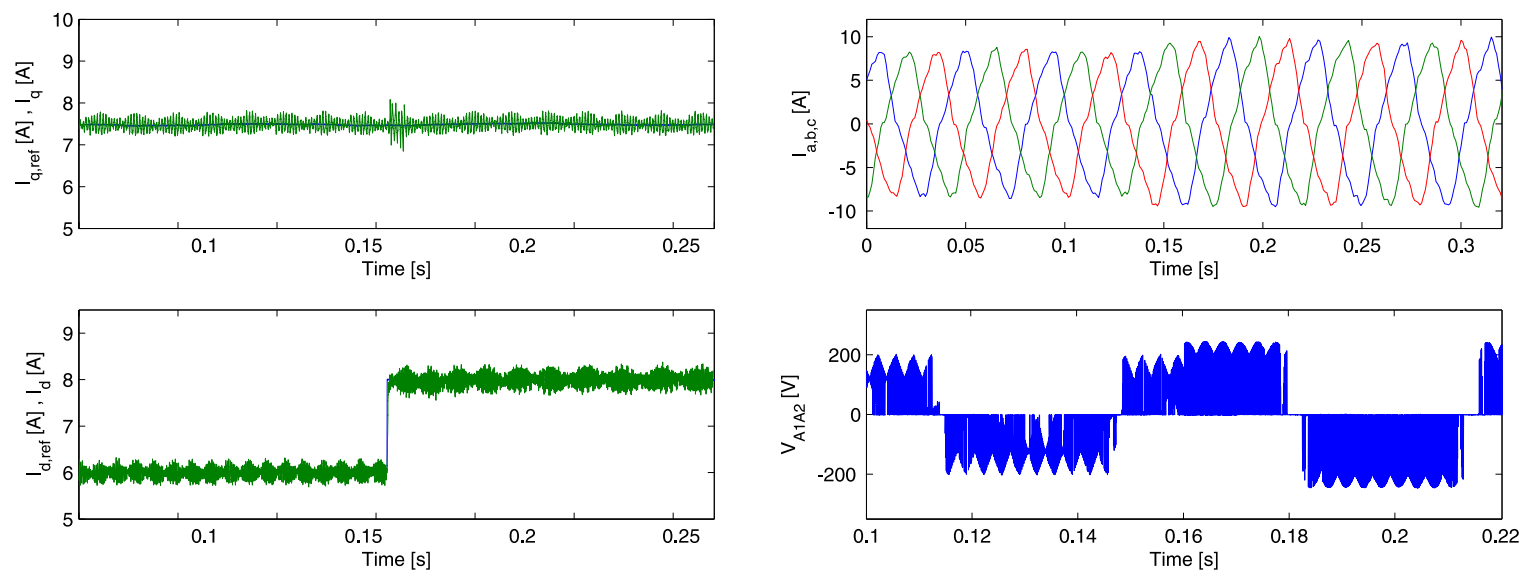

a)

b)

Fig. 12: $d$-axis current step change. a) Motor $q$-axis current (top) and $d$-axis current (bottom). b) Motor currents (top) and phase voltage (bottom)

Simulation results presented in Fig. 7a and the experimental results in Fig. 11a are very similar with a slight transient difference due to a mismatch between the simulation parameters, used for tuning the currents PI controllers, and the real parameters in the machine. The same applies for the simulation and experimental results presented in Figures 8a and 12a respectively. 
Finally, Fig. 13 (top) shows the input phase voltage and current with an input power factor close to unity, a similar situation to the simulation results depicted in Fig. 9. The zero sequence voltage is shown in Fig. 13 (bottom). The zero sequence voltage is obtained by measuring the corresponding voltages to apply (4). It can be noticed that the zero sequence voltage is not exactly zero, compared with Fig. 9 in the simulation results. This is probably due to the measurement procedure because the channels are not sampled at the same time and because of non-idealities in the switches which are not accounted for in the model used in the simulation.
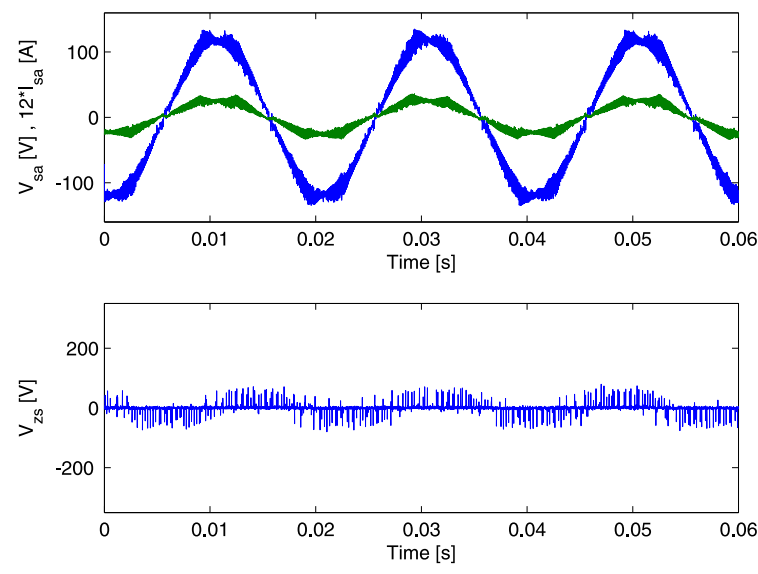

Fig. 13: Input rectifier voltage and current (top) and zero sequence voltage (bottom)

\section{Conclusions}

The development of a drive using an open-ended winding induction motor drive fed by an IMC has been presented. Two modulation strategies can be used for the input rectifier, depending on the output voltage requirement. One modulation strategy aims for a maximum positive DC voltage and the other modulation strategy aims for a reduced positive DC voltage. Regardless of the modulation strategy used for the rectifier, unity displacement power factor operation is achieved at the converter input. On the other hand, the modulation strategy used for the output stages of the IMC is intended to reduce the zero sequence voltage in order to avoid the occurrence of zero sequence current in the machine. An indirect feedforward vector control scheme has been implemented for drive control and good performance of the control scheme has been verified for a step changes in the $d q$-axis reference currents. Simulation and experimental results have been presented confirming the viability of the proposed topology and control strategy.

\section{References}

[1] Yang Wang; Panda, D.; Lipo, T.A; Di Pan, "Open-Winding Power Conversion Systems Fed by HalfControlled Converters," Power Electronics, IEEE Transactions on , vol.28, no.5, pp.2427,2436, May 2013.

[2] Wang, Y.; Lipo, T.A; Pan, D., "Robust operation of double-output AC machine drive," Power Electronics and ECCE Asia (ICPE \& ECCE), 2011 IEEE 8th International Conference on , vol., no., pp.140,144, May 30 2011-June 32011.

[3] Wheeler, P.W.; Rodriguez, J.; Clare, J.C.; Empringham, L.; Weinstein, A, "Matrix converters: a technology review," Industrial Electronics, IEEE Transactions on, vol.49, no.2, pp.276,288, Apr 2002.

[4] Kolar, J.W.; Friedli, T.; Rodriguez, J.; Wheeler, P.W., "Review of Three-Phase PWM AC-AC Converter Topologies," Industrial Electronics, IEEE Transactions on , vol.58, no.11, pp.4988,5006, Nov. 2011.

[5] Gupta, R.K.; Mohapatra, K.K.; Somani, A; Mohan, N., "Direct-Matrix-Converter-Based Drive for a ThreePhase Open-End-Winding AC Machine With Advanced Features," Industrial Electronics, IEEE Transactions on, vol.57, no.12, pp.4032,4042, Dec. 2010.

[6] Sandulescu, P.; Meinguet, F.; Kestelyn, X.; Semail, E.; Bruyere, A., "Control Strategies for Open-End Winding Drives Operating in the Flux-Weakening Region," in Power Electronics, IEEE Transactions on, vol.29, no.9, pp.4829-4842, Sept. 2014. 
[7] Kubo, H.; Yamamoto, Y.; Kondo, T.; Rajashekara, K.; Bohang Zhu, "Deadbeat current control for openend winding induction motor using current prediction with two different time-horizons," in Energy Conversion Congress and Exposition (ECCE), 2015 IEEE, vol., no., pp.2169-2175, 20-24 Sept. 2015.

[8] Bohang Zhu; Rajashekara, K.; Kubo, H., "Predictive torque control with zero-sequence current suppression for open-end winding induction machine," in Industry Applications Society Annual Meeting, 2015 IEEE, vol., no., pp.1-7, 18-22 Oct. 2015.

[9] Somani, A.; Gupta, R.K.; Mohapatra, K.K.; Basu, K.; Mohan, N.; , "Modulation strategies for direct link drive for open-end winding AC machines," Electric Machines and Drives Conference, 2009. IEMDC '09. IEEE International, vol., no., pp.1863-1868, 3-6 May 2009.

[10] Pena, R.; Cardenas, R.; Reyes, E.; Clare, J.; Wheeler, P., "Control of a Doubly Fed Induction Generator via an Indirect Matrix Converter With Changing DC Voltage," Industrial Electronics, IEEE Transactions on , vol.58, no.10, pp.4664,4674, Oct. 2011.

[11] Riedemann, J.; Pena, R.; Cardenas, R.; Clare, J.; Wheeler, P.; Blasco-Gimenez, R., "Control strategy of a dual-inverter system for an open-end winding induction machine based on indirect matrix converter," Power Electronics and Applications (EPE'14-ECCE Europe), 2014 16th European Conference on, vol., no., pp.1,8, 26-28 Aug. 2014.

[12] Klumpner, C.; Blaabjerg, F.; , "Modulation method for a multiple drive system based on a two-stage direct power conversion topology with reduced input current ripple," Power Electronics, IEEE Transactions on , vol.20, no.4, pp. 922-929, July 2005.

[13] J.W. Kolar, F. Schafmeister, "Novel modulation schemes minimizing the switching losses of sparse matrix converters" Novel modulation schemes minimizing the switching losses of sparse matrix converters". The $29^{\text {th }}$ Annual Conference of the IEEE Industrial Electronics Society, 2003. IECON '03, Vol. 3, pp. $2085-$ 2090. Roanoke,VA, USA. 2003.

[14] Somasekhar, V.T.; Srinivas, S.; Prakash Reddy, B.; Nagarjuna Reddy, C.; Sivakumar, K.; , "Pulse widthmodulated switching strategy for the dynamic balancing of zero-sequence current for a dual-inverter fed open-end winding induction motor drive," Electric Power Applications, IET , vol.1, no.4, pp.591-600, July 2007.

[15] Riedemann, Javier; Pena, Ruben; Cardenas, Roberto; Clare, Jon; Wheeler, Pat; Rivera, Marco, "Switching strategies for an indirect matrix converter fed open-end load," Industrial Electronics (ISIE), 2013 IEEE International Symposium on , vol., no., pp.1,6, 28-31 May 2013.

[16] W. Leonhard, Control of Electrical Drives. Berlin: Springer, 2001. 


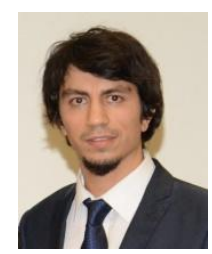

Javier Riedemann was born in Punta Arenas, Chile. He received the electrical engineering degree from the University of Magallanes, Punta Arenas, Chile, in 2010 and the D.Sc. degree from the University of Concepción, Concepción, Chile, in 2015. He is currently a lecturer at the Department of Electrical and Electronics Engineering, University of Bío-Bío, Concepción, Chile. His main interests are in control of power electronics converters and variable speed ac drives.

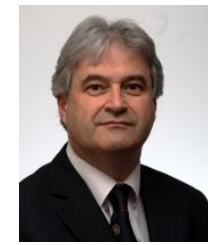

Jon C. Clare was born in Bristol, U.K., in 1957. He received the B.Sc. and Ph.D. degrees in electrical engineering from the University of Bristol, Bristol. From 1984 to 1990, he was a Research Assistant and Lecturer with the University of Bristol, where he was involved in teaching and research on power electronic systems. Since 1990, he has been with the Power Electronics, Machines and Control Group, The University of Nottingham, Nottingham, U.K., where he is currently a Professor of power electronics. His research interests include power-electronic converters and modulation strategies, variable-speed-drive systems, and electromagnetic compatibility.

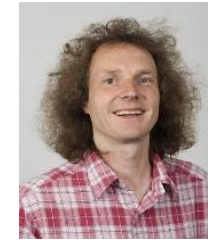

Pat W. Wheeler received the B.Eng. (Hons.) degree in, 1990, and the Ph.D. degree in electrical engineering for his work on matrix converters, in 1994, both from the University of Bristol, Bristol, U.K. In 1993, he moved to the University of Nottingham, Nottingham, U.K., and worked as a Research Assistant in the Department of Electrical and Electronic Engineering. In 1996, he became a Lecturer in the Power Electronics, Machines and Control Group, The University of Nottingham. Since January 2008, he has been a Full Professor in the same research group. He has published 400 academic publications in leading international conferences and journals. Dr. Wheeler is a Member at Large and Distinguished Lecturer of the IEEE Power Electronics Society.

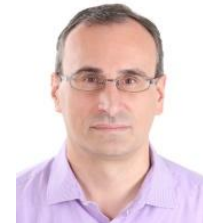

Ramón Blasco-Gimenez obtained his BEng degree in Electrical Engineering from the Universitat Politecnica de Valencia, Spain, in 1992 and his PhD degree in Electrical and Electronic Engineering from the University of Nottingham, UK, in 1996. From 1992 to 1995 he was a Research Assistant at the Dept. of Electrical and Electronic Engineering of the University of Nottingham. In 1996 he joined the Dept. of Systems Engineering and Control of the Universitat Politécnica de Valencia, where he is an Accredited Professor. His research interests include Control of HVdc systems, Wind Power Generation and Grid Integration of Renewable Energy Systems. He is a co-recipient of the 2004 IEEE Transactions on Industrial Electronics Best Paper Award. He has been guest co-editor of The IEEE Transactions on Energy Conversion and The Mathematics and Computers in Simulation journals. He is a Chartered Engineer (U.K.), IET member, IMACS TC1 Committee member and Chair of the Renewable Energy Technical Committee of the IEEE Industrial Electronics Society.

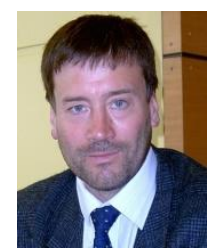

Roberto Cárdenas was born in Punta Arenas, Chile. He received the B.S. degree from the University of Magallanes, Punta Arenas, in 1988 and the M.Sc. and Ph.D. degrees from The University of Nottingham, Nottingham, U.K., in 1992 and 1996, respectively. During 1989-1991 and 1996-2008, he was a Lecturer with the University of Magallanes. From 1991 to 1996, he was with the Power Electronics Machines and Control Group, The University of Nottingham. During 2009-2011, he was with the Electrical Engineering Department, University of Santiago, Santiago, Chile. He is currently a Professor of power electronics and drives with the Electrical Engineering Department, University of Chile, Santiago. His main interests include control of electrical machines, variable-speed drives, and renewable energy systems. Dr. Cárdenas received the Best Paper Award from the IEEE TRANSACTIONS ON INDUSTRIAL ELECTRONICS in 2005. He is an Associate Editor of the IEEE TRANSACTIONS ON INDUSTRIAL ELECTRONICS

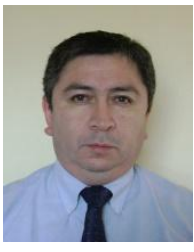

Rubén Peña was born in Coronel, Chile. He received the Electrical Engineering degree from the Universidad de Concepcion, Concepcion, Chile, in 1984, and the M.Sc. and Ph.D. degrees from the University of Nottingham, Nottingham, U.K., in 1992 and 1996, respectively. From 1985 to 2008, he was a Lecturer in the Universidad de Magallanes, Chile. He has been with the Electrical Engineering Department, Universidad de Concepcion, since 2008, where he is currently a Full Professor. His main interests include control of power electronics converters, ac drives, and renewable energy systems. Dr. Pena received the Best Paper Award from the IEEE TRANSACTIONS ON INDUSTRIAL ELECTRONICS in 2004, and the Ramon Salas Edward Award for research excellence from the Chilean Institute of Engineers in 2009. 